\title{
1. Introduction: newcomers in aviation
}

\subsection{A PILOT NOT INSIDE THE AIRCRAFT?}

On 7 March 2018, the Council of the International Civil Aviation Organization (ICAO), ${ }^{1}$ based on a proposal ${ }^{2}$ by the Air Navigation Commission (ANC) on which ICAO Contracting States had been consulted, ${ }^{3}$ adopted a brand new Remote Pilot Licence (RPL). Although this new licence will become applicable only on 3 November 2022, it can already be observed that it is very innovative for at least four reasons:

1. The pilot is no longer inside the fuselage of an aircraft, but remote from the aircraft itself and uses digital signals to control the flight;

2. The pilot licence is not issued, as is usual, by the State where the aircraft is registered, but by the State where the organisation of the operator is established;

3. There is no longer any distinction between private and commercial pilots, since the risk for third parties in the air or on the ground is identical; and

4. Differently from the traditional Commercial Pilot Licence (CPL) for manned aircraft, which may not be initially accompanied by an Instrument Rating (IR), the RPL always encompasses at its first issue the privilege to fly under Instrument Flight Rules (IFR), since flying drones in international operations under Visual Flight Rules (VFR) is neither of interest for operational and business purposes, nor easily feasible.

From the introductory text above, readers may already realise how radically different civil drones are in respect of traditional aviation from the regulatory and safety points of view.

1 A specialised Agency of the United Nations.

2 International Civil Aviation Organization (ICAO), President of the Air Navigation Commission, Adoption of amendment 175 to Annex 1, Council Working Paper C-WP/14714, Montreal, 31 January 2018.

3 ICAO, Proposals for the amendment of Annexes 1, 2 and PANS-TRG (Doc 9868) related to remotely piloted aircraft systems (RPAS), State Letter type I AN 12/1.1.22-17/53, Montreal, 3 May 2017. 


\subsection{PURPOSE AND SCOPE}

The purpose of this book is to summarise the 'revolution' in the regulatory approach triggered by drones in civil aviation, in the safety domain, but also in other relevant social aspects such as security, liability, insurance, privacy and data protection. Since safety regulation is, on the one hand, embedded into legislation, and on the other hand, grounded in technical facts, the aim of this book is to explain legal aspects to readers not experienced in law and, conversely, to explain key technical facts to jurists, economists or other non-technical professionals. Hence, it is hoped that this book may be useful to any person interested in the regulation of nonmilitary drones, including experts who would find some history and some rationale behind the regulations. Full understanding of the regulations may in fact be very important to define any business case for commercial applications of civil drones, which are expected to dramatically increase in the immediate future, in Europe, ${ }^{4}$ the $\mathrm{US}^{5}$ and elsewhere.

Finally, this book could potentially be useful to people deeply conversant with one aviation domain, but not necessarily conversant with regulatory aspects in other domains. In fact, the scope covers the history of aviation safety regulation, societal concerns related to drones, taxonomy and categorisation of both drones and drone operations, risk-based approach to drone regulation, security, liability and insurance issues, privacy and data protection and the classical domains of aviation safety: airworthiness, crew competence and operations.

Due to lack of space, but also insufficient current standardisation on the global scale, specific topics such as Unmanned Aircraft System(UAS) Traffic Management (alias UAS Traffic Management (UTM) in the U-Space), geofencing, electronic identification, 'Detect and Avoid' (DAA) and 'Command and Control' (C2) data link are outside the scope of this book.

\subsection{DO WE NEED A PILOT ON-BOARD THE AIRCRAFT?}

The dream of using devices to lift humans into the air was conceived by our ancestors, as in the myth of Icarus, and later based on accurate observation

4 Single European Sky ATM Research (SESAR) Joint Undertaking, 'European drones outlook study - unlocking the value for Europe', Brussels, November 2016.

5 Federal Aviation Administration (FAA), 'Aerospace forecast 2017-37 unmanned aircraft systems', Washington, April 2017. 
of birds, for instance, by Leonardo Da Vinci. To explain drones, the authors prefer, however, not to start from the history of aviation, but from a common device in our daily life: the lift installed in many residential or commercial buildings around our towns. It was during the age of the Industrial Revolution, in the nineteenth century, that modern lifts were manufactured, using steam or another form of energy. In 1853, Elisha Graves Otis invented a brake to prevent free fall of the cabin, even in the case of broken cables. A few years later, the first 'public' lift was inaugurated in a department store in New York. At that time, however, the device was too new for citizens and the technology was not always reliable: it was therefore common to encounter a lift operator moving levers or pushing buttons to command the lift and act in case of failure. We all know that nowadays these personnel have disappeared from most buildings, while we operate the lifts by ourselves, without the need for a specific professional competence. In other words, contemporary lifts are 'unmanned', because they do not require a professionally skilled person on-board to manoeuvre them.

Equally, since steam engines pulling trains on rails spread after 1820 , for a century and a half it was not conceivable to have an engine without an operator on-board. But, since the beginning of the twenty-first century, trains without a human operator on-board have been emerging in airports and on several metropolitan underground lines.

In aviation the crew of the first generation of B-747 (so-called 'Jumbo Jet') which entered into service in 1970, was composed of five members: captain, co-pilot, navigator, flight engineer and radio operator. Progressively, the required flight crew members of large transport aeroplanes have been reduced to only the captain and the co-pilot; but technology would already allow flight with no crews on-board. Societal concerns, regulations and the psychological attitude of the potential passengers, beside safety and reliability arguments, will still demand, in the humble opinion of the authors of this book, at least one pilot on-board large passenger aircraft for several decades to come. This, however, does not prevent civil drones from being exploited for other aviation services, mainly for aerial work, ${ }^{6}$ especially when these operations are 'dull, dirty and dangerous'.

Furthermore, the idea of flying machines with no crew on-board is also quite old. Centuries ago in China, kites decorated with brilliant colours were flown during festivals and similar events. In 1849, when

6 'Aerial work' is defined by the ICAO as an aircraft operation in which an aircraft is used for specialised services such as agriculture, construction, photography, surveying, observation and patrol, search and rescue, aerial advertisement, etc. Air transport of persons, freight or mail does not belong to aerial work. Equally, recreational general aviation is not aerial work. 
the Austro-Hungarian Army was laying siege to Venice, they launched a fleet of unmanned free balloons loaded with explosives, in an attempt to bomb the city. Luckily, technology was not sufficiently mature for the attack to be successful. Nevertheless, this fact is a demonstration that military authorities had already identified the potential of drones, although the term 'drone' was not yet applied to unmanned aircraft at that time.

Among the first unmanned fixed wing aeroplanes, the 'Kettering Bug' tested in the US in 1917 during the First World War should be mentioned. After the War, several attempts were made to fly radio-controlled aircraft, mainly to serve as aerial targets to train fighter pilots for air-to-air combat. One of the most famous was a modified British 'Tiger Moth' manufactured by De Havilland in 1935. Since its purpose was to be chased by fighter aircraft, like a queen bee in nature is chased by drones (i.e. the real insects), that aerial target was nicknamed 'Queen Bee'. This is probably one reason why smaller unmanned aircraft started to be called 'drones'.

During the Second World War, small radio-controlled aircraft were frequently used as aerial targets. Marilyn Monroe at the time worked in a factory producing aerial targets. This use continued for decades, but it constituted a very small niche of aviation activities.

\subsection{TOWARDS REGULATION OF CIVIL UNMANNED AIRCRAFT}

The turning point was in 1991 when, during the war in the Persian Gulf, the US military services and their allies realised that the potential of drones for military applications was wide ranging. Following these experiences, the manufacturing industry not only increased the production of military drones, but soon started to promote their civil use. The first civil aviation authority promulgating rules for the civil use of drones was the Danish Civil Aviation Authority (CAA) 7 in 1986. Few others followed in the first years of the twenty-first century. Between 2002 and 2004, a joint task force, established by the European Joint Aviation Authorities (JAA; precursor of the European Aviation Safety Agency - EASA) and EUROCONTROL concluded ${ }^{8}$ that drones were aircraft, and hence in

7 Denmark Civil Aviation Administration, 'Regulations on unmanned aircraft not weighing more than 25 kg', BL 9-4, Edition 1, Copenhagen, 1986.

8 Joint Aviation Authorities (JAA)/European Organisation for the Safety of 
the regulatory competence of the aviation authorities, starting with the ICAO at the global level. The same conclusion had been reached by the European legislator, which included civil unmanned aircraft above $150 \mathrm{~kg}$ in the remit of the EASA in 2002, ${ }^{9}$ as well as, in 2007 by standard-making bodies such as the Radio Technical Commission for Aeronautics (RTCA) and EUROCAE. The limit of $150 \mathrm{~kg}$ has been recently replaced by the new basic regulation which extends EASA competencies to unmanned aircraft with a maximum take-off mass less than $150 \mathrm{~kg} .{ }^{10}$

This growing consensus of the community with regards to the fact that drones were aircraft, led the ICAO to establish in 2007 a Study Group on the matter. Meanwhile, Chinese manufacturers started to produce and sell small drones weighing only a couple of kilograms all over the world. The attention of the ICAO focused nevertheless on the large 'Remotely Piloted Aircraft Systems' (RPAS) able to fly under IFR on a global scale. In Europe there was a debate on whether priority should be given to regulate the large or the small drones, which initiated with a high-level conference in 2010. The European conclusions at that time stressed the urgency of regulating the small ones and this was enshrined by the political authorities in 2015 in the Riga declaration. ${ }^{11}$ One year later, following these developments, the US Federal Aviation Administration (FAA) published its first rules ${ }^{12}$ on small UASs, labelling these machines 'aircraft'. Even more importantly, Part 107 was published by the FAA, which provides evidence that civil drones are considered aircraft and hence in the remit of the FAA by the US Government.

Air Navigation (EUROCONTROL) joint initiative on UAVs, UAV Task-Force final report, 'A concept for European regulations for civil unmanned aerial vehicles (UAVs)', Hoofddorp, 11 May 2004.

9 Regulation (EC) No 1592/2002 of 15 July 2002 on common rules in the field of civil aviation and establishing a European Aviation Safety Agency [2002] OJ L240/1 (now replaced by Regulation (EU) 1139/2018).

10 Regulation (EU) No 1139/2018 of the European Parliament and of the Council of 4 July 2018 on common rules in the field of civil aviation and establishing a European Union Aviation Safety Agency, and amending Regulations (EC) No 2111/2005, (EC) No 1008/2008, (EU) No 996/2010, (EU) No 376/2014 and Directives 2014/30/EU and 2014/53/EU of the European Parliament and of the Council, and repealing Regulations (EC) No 552/2004 and (EC) No 216/2008 of the European Parliament and of the Council and Council Regulation (EEC) No $3922 / 91$. It is worth reiterating here the new definition of 'unmanned aircraft' that means any aircraft operating or designed to operate autonomously or to be piloted remotely without a pilot on-board.

11 EU, Riga declaration on remotely piloted aircraft (drones), 'Framing the future of aviation', Riga, 6 March 2015.

12 FAA, 'Small unmanned aircraft rule', Part 107, Washington, 21 June 2016. 
In just over three decades between 1986 and 2018 (e.g. introduction of RPL in Annex 1 to the Chicago Convention), the civil aviation community dug new ground and ideas started to be formalised in emerging regulations which are still taking shape.

The aim of this book is both to explain these developments and to enable readers to understand the direction in which the community is moving, as well as to prepare the community itself for the imminent new regulatory events which could also be influenced in the appropriate forums, using the information provided in these pages. 